MATEC Web of Conferences 40, 05004 (2016)

DOI: $10.1051 /$ matecconf $/ 20164005004$

(C) Owned by the authors, published by EDP Sciences, 2016

\title{
Definition of the Heat Resistance of Three-layer Ferroconcrete Panel
}

\author{
Gregory P. Vasilyev ${ }^{1}$, Vitaly A. Leskov ${ }^{1,}{ }^{2}$, Victor F. Gornov ${ }^{1}$, Vladimir A. Lichman ${ }^{3}$, Marina V. Kolesova ${ }^{4}$ \\ Alexander N. Dmitriev ${ }^{5}$ \\ ${ }^{1}$ JSC «NIIMosstroy», Moscow, Russia, 119192, Moscow, Vinnitskaya Street, house 8 \\ ${ }^{2}$ JSC «Insolar-Energo», Moscow, Russia, 121433, Moscow, Filevskaya Street, house 32, building 3 \\ ${ }^{3}$ "JSC -INVEST», Moscow, Russia, 121433, Moscow, Filevskaya Street, house 32, building 3 \\ ${ }^{4}$ "JSC -Energo», Moscow, Russia, 121433, Moscow, Filevskaya Street, house 32, building 3 \\ ${ }^{5}$ Department of Economics and Managing the City Construction, Engineering and Economic Faculty of the Russian Plekhanov Economic \\ Academy, Russia, 115054, Moscow
}

\begin{abstract}
This work describes the method of calculation of resistance referred to heat transfer of fencing in construction of an edifice with an example of a tree-layered ferroconcrete panel. In the limits of a final element program medium, a numerical modeling of stationary distributions of temperature fields and heat flows of panels of a type story of an apartment house have been conducted. On the basis of the results of numeral modeling the value of resistances to heat transfer and of the factors of termotechnical uniformity of panels are calculated.
\end{abstract}

\section{Introduction}

In order to improve the heating/engineering qualities of the exterior wall panels, the designers and producers must know the value of resistance to the heat transfer and of the heat-engineering uniformity of eachpiece of work, wall panel not insulated, but fitted to the structure of standart story of a multistory apartment house. In order to exclude the influence of «heat briges». It is necessary to conduct the calculation of temperature fields of all the nodes around the panel, to get information about overflow of heat flows in the whole structure. The conduction of three-dimensional calculation for solution of this problem often presents itself sufficiently laborious. The most successful method of calculation is the apportionment of construction elements according to the dimensionality of their projections: plane, linear and point [1-4].

\section{Determination of the resistance refered to the heat transfer of a panel}

As fragments of fencing in construction of an edifice we will pick out the panels of a typ story. The calculations we will conduct with an example of a deaf three-layered ferroconcrete panel of MH-7 111M type of the construction system. In each fragment (panel) we will pick out there types of elements according to the dimensionality of their projections: plane, liner and point [1-4]. The plane elements, with summary area of $\sum A_{i}^{(2)}$, are lots of uniform specific density of a heat flow,-a «smooth surface» of the fencing in construction». The heating- engineering characteristics of the plane elements may be estimated from simple analytical expression. The linear elements, with summary area of $\sum A_{j}^{(1)}$ our butts of panels, window and door slopes, nodes of interstorey overlaps, and so on -are the elements at which one dimension is essentially less than another and is small in comparison with the dimensions of the considered elements of the fencing in construction. The linear elements may be modeled in the Cartesian coordinates as two dimensional problems. The point elements with the summary area of $\sum A_{k}^{(0)}$ are metallic connections of panels, dowels, pins and so on are the elements at which the dimensions of their projection on the surface of fencing// in are small in comparison with the area of the considered fragment. The pointwise elements must be modeled in the Cartesian coordinates in a threedimensional, or two-dimensional in cylindrical coordinates. In that way, the total area of the panel, fragment of the tencing in construction is $A=\sum A_{i}^{(2)}+\sum A_{j}^{(1)}+\sum A_{k}^{(0)}$ Picking out three types of elements we will write down the formula for calculation of the value $R_{0}^{r}$ of the reduced resistance to heat transfer panel $m^{2} \cdot K / W[5]$ 
$R_{0}^{r}=\frac{\left(t_{\mathrm{int}}-t_{\text {ext }}\right)}{q^{r}}=\left[\frac{1}{R_{0}}+\sum \frac{A_{j}^{(1)}}{A} \frac{\Delta q_{j}^{(1)}}{\left(t_{\mathrm{int}}-t_{\text {ext }}\right)}+\sum \frac{A_{k}^{(0)}}{A} \frac{\Delta q_{k}^{(0)}}{\left(t_{\mathrm{int}}-t_{\text {ext }}\right)}\right]^{-1}$

Where $q^{r}=\int q d A / A$-is the referred density ot the A

heat flow $W / m^{2} ; t_{\text {int }}, t_{\text {ext }}$ - are the rated temperatures of the internal and outdoor air ${ }^{0} C ; \Delta q_{j}^{(1)}=\left(q_{j}^{2 D}-q_{0}\right)$ - is the value of additional heat losse through the linear heating-engineering of the j- type $W / m^{2}$; $\Delta q_{k}^{(0)}=\left(q_{k}^{3 D}-q_{0}\right)$-is the value of additional heat losses through the point of heating-engineering heterogeneity of the k-type, $W / m^{2}$

The value of the conditional density of the heat flow $q_{0}, W / m^{2}$ - is calculated from the correlation: $q_{0}=\left(t_{\text {int }}-t_{\text {ext }}\right) / R_{0}$ The resistance to the heat transfer of the panel accordind to the «smoth surface»$R_{0}$-the conditional resistance to the heat transfer$\cdot m^{2} K / W$ may be calculated analytically:

$R_{0}=\frac{1}{\alpha_{\text {int }}}+\sum_{i=1}^{n} \frac{d_{i}}{\lambda_{i}}+\frac{1}{\alpha_{\text {ext }}}$

Where $\alpha_{\text {int }}, \alpha_{\text {ext }}$ are the heat transfer coefficients of the internal and external surface of the construction node, repectively, $W /\left(m^{2} \cdot K\right) ; d_{i}$-is the layer thickness; $\lambda_{i}$ - is the coefficient of thermal conductivity of the material of the $i-$ th layer, $W /(m \cdot K)$.The formula for the calculation of the resistance referred to the heat transfer of the panel(1) may be comfortably presented in the following form:

$$
R_{0}^{r}=A \cdot\left[\frac{A}{R_{0}}+\sum L_{j} \psi_{j}+\sum \chi_{k}\right]^{-1}
$$

Where $\psi_{j}=h_{j} \cdot\left(q_{j}^{2 D}-q_{0}\right) /\left(t_{\text {int }}-t_{\text {ext }}\right)$-is the linear heat transfer coefficient; $W /(m \cdot K)$; $\chi_{k}=A_{k}^{(0)}\left(q_{k}^{3 D}-q_{0}\right) /\left(t_{\text {int }}-t_{\text {ext }}\right)$-is the point coefficient of the heat transfer, $W / K ; A_{j}^{(1)}=L_{j} \cdot h_{j}$ -is the area of the linear $j$-element, $m^{2} ; L_{j}$ - is extension, ${ }^{m} ; h_{j}$-is width; $A_{k}^{(0)}$-is the area of the kelement, $m^{2}$.The density of the heat flow $q_{j}^{2 D}, W / m^{2}$-is determined by the two-dimensional computer modeling of heat processes for theconstruction. The density of heat flow $q_{k}^{3 D}, W / m^{2}$-is determined by the three-dimensional computer modeling of heat processes for the preset construction.The heat-engineering uniformity coefficient of a panel:

$$
r=q_{0} / q^{r}=R_{0}^{r} / R_{0}
$$

The heat-engineering two-dimensional and threedimensional calculations are executed by the solution of the stationary problem of heat conduction in the limits of the final elementary program complex. The boundary conditions of the 3-rd type were selected as the convective heat exchanges in nodes: on the internal surface of a wall with the convective heat transfer factor $\quad \alpha_{\text {int }}=8.7 \cdot \mathrm{W} /\left(\mathrm{m}^{2} \mathrm{~K}\right) \quad$ and calculation temperature within apartment $t_{\text {int }}=20 \cdot{ }^{\circ} \mathrm{C}$ on the external surface of a wall $\alpha_{\text {ext }}=23 \cdot \mathrm{W} /\left(\mathrm{m}^{2} \mathrm{~K}\right)$ and the calculation temperature of the environment $t_{\text {ext }}=-28^{\circ} \mathrm{C}$. Various design elements were assigned to their corresponding thermal characteristics of materials. The coefficients of thermal conductivities of materials walling: for insulation, polystyrene type "Neopor", $\quad \lambda=0.037 \cdot \mathrm{W} /(\mathrm{m} \cdot \mathrm{K}) \quad ; \quad$ ferroconcrete $\lambda=2.04 \cdot \mathrm{W} /(\mathrm{m} \cdot \mathrm{K}) \quad ; \quad$ metallic bonds $\lambda=58 \cdot W /(m \cdot K) \quad$ warmth keeping-type Wiltern $\lambda=0.06 \cdot \mathrm{W} /(\mathrm{m} \cdot \mathrm{K}) \quad ; \quad$ cement-sand solution $\lambda=0.93 \cdot \mathrm{W} /(\mathrm{m} \cdot \mathrm{K})$ The thickness of three-layer reinforced concrete panels: the outer concrete layer 80 $\mathrm{mm}$. that of warmth keeping jacket $150 \mathrm{~mm}$, that of internal concrete layer $170 \mathrm{~mm}$. The resistance to the heat transfer of the panel according to the smooth surface calculated from correlation (3) is equal to $R_{0}=4.34 \cdot m^{2} \cdot K / W$ the relative density of the Reat How is equal to $q_{0}=11.1 \cdot \mathrm{W} / \mathrm{m}^{2}$ the $\mathrm{MH}-7$ type panels area $A=3.25 \cdot 2.8=9.1 \cdot \mathrm{m}^{2}$.

The considered wall panel of $\mathrm{MH}-7$ type has two vertical butts with designations «node 1-2» and «nod 14» and two horizontal butts with designation sector BB. Some results of numeral modeling of stationaty distribution of temperature fields and heat flows are brought on Fig. 1-2 On Fig.2 the additional heat losses are distinctly seen through a heat bridge of the node the interstorey overlap (B-B) which are displayed as an exceeding of the value of the conditional density of the heat flow $q_{0}=11.1 \cdot \mathrm{W} / \mathrm{m}^{2}$ 


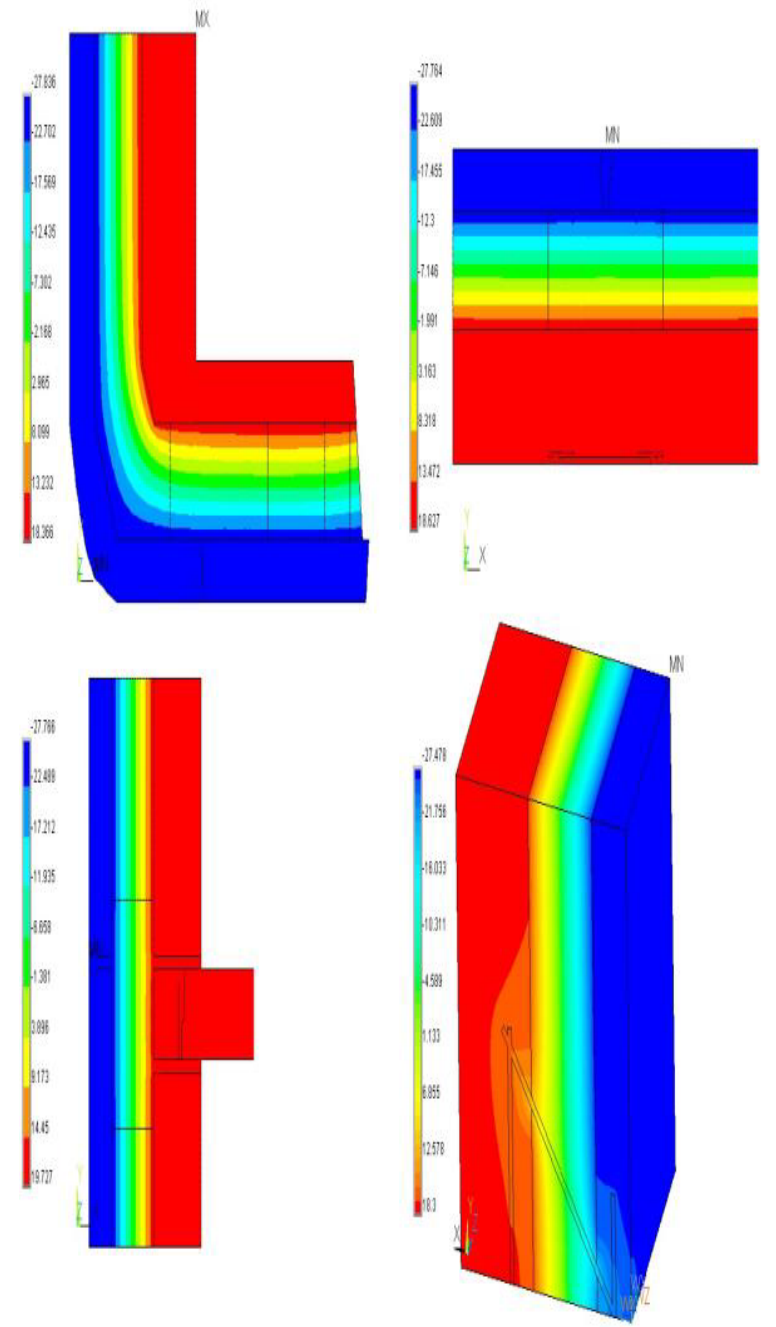

Figure 1. Simulation Results of distribution of temperature fields in two-dimensional models of the node 1-4 (top left), node 1-2 (top right) cross-section B-B (bottom left) and three-dimensional model of the area of the metallic bond (bottom right) three-layer reinforced concrete panelsreinforced concrete panels

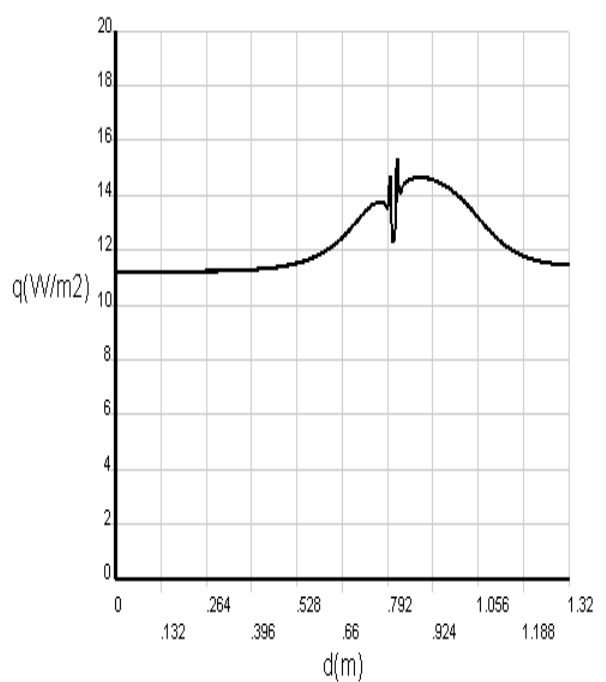

Figure 2. Distribution of the density of heat flow on the external surface of section B-B.

The additional heat losses through the heat bridge of the node of interstorey overlap are displayed as exceeding of the value of heat flow over the meaning of the conditional densing of heat flow $q_{0}=11.1 \cdot \mathrm{W} / \mathrm{m}^{2}$. The obtained distributions of the densities of heat flows on the external side of the construction are used for obtaining of values $q_{j}^{2 D}, W / m^{2}$ and respectively, of $\psi_{j}, W /(m \cdot K)$. The integration was conducted in the limits of values of each node and section. The density of heat flows in the section $\mathrm{B}-\mathrm{B}$ is equal to $q_{1}^{2 D}=12.6 \cdot \mathrm{W} / \mathrm{m}^{2}$, value $\psi_{1}=0.026 \cdot \mathrm{W} /(\mathrm{m} \cdot \mathrm{K})$. The results of calculations for the panel elements of MH-7 type having linear heatengineering heterogeneities are taken down to Table 1.

Table 1. Results of calculations for panels of MH-7 type

\begin{tabular}{|l|l|l|l|l|}
\hline$№$ & $\begin{array}{l}\text { Elements of } \\
\text { construction } \\
\text { having } \\
\text { linear heat- } \\
\text { engineering } \\
\text { heterogeneti } \\
\text { es }\end{array}$ & $A_{j}^{(1)}, \cdot m^{2}$ & $q_{j}^{2 D}, W / m^{2}$ & $\psi_{j}, W /(m \cdot K)$ \\
\hline 1 & Node 1-4 & 1.12 & 17.7 & 0.055 \\
\hline 2 & Node 1-2 & 1.12 & 12.4 & 0.011 \\
\hline 3 & Section B-B & 1.96 & 12.6 & 0.026 \\
\hline
\end{tabular}

The density of heat flows received by the threedimensional computer modeling in the region of flexible metallic bonds is equal to $q_{1}^{3 D}=13.1 \cdot \mathrm{W} / \mathrm{m}^{2}$ value $\chi_{1}=0.018 \cdot \mathrm{W} / \mathrm{K}$; the radius of influence of one bond- $0,25 \cdot m$ In the considered panel 12 metallic bonds have available, the summary area of influence of all the metallic bonds is equal to $\sum A_{k}^{(0)}=12 \cdot 3.14 \cdot 0,25^{2}=2.83 \cdot m^{2} \quad$ The referred resistance of heat transfers to panels of $\mathrm{MH}-7$ type is determined from expression (3), $-R_{0}^{r}=3.63 \cdot \mathrm{m}^{2} \cdot \mathrm{K} / \mathrm{W}$. The factor of heat engineering uniformity is equal to $r=R_{0}^{r} / R_{0}=3.63 / 4.34=0.84$.

Analogically, the numeral modeling is conducted for stationary distributions of temperature fields and heat flows of the all types of panels of the standart storey of an apartment house. Table 2 shows the results of thermal resistance calculations for all the panels of a 
standard storey of a 2-section apartment house of $111 \mathrm{M}$ construction system. For panels located inside the balconies the value of thermal resistance is divided by

$n=\left(t_{\text {int }}-t_{b}\right) /\left(t_{\text {int }}-t_{\text {ext }}\right)=(20-(-21.8)) /(20-(-48))=0.87$, where the temperature inside the balconies $t_{b}=-21.8 \cdot{ }^{0} C$ is calculated based on the heat balance equation. Therefore, the thermal resistance value of a standard storey equals $R_{0}^{r}=3.48 \cdot m^{2} \cdot K / W$, thermal uniformity coefficient is $r=0.79$..

Table 2. Results of thermal resistance calculations for all the panels of a standard storey of a 2-section apartment house of $111 \mathrm{M}$ construction system

\begin{tabular}{|c|c|c|c|c|}
\hline № & Paneltype & $\begin{array}{l}\text { Area of the } \\
\text { opaque part } \\
\text { of the panel } \\
\mathrm{m}^{2}\end{array}$ & $R_{0}^{r},\left(m^{2} \cdot K\right) / \mathrm{W}$ & $\begin{array}{l}\text { Therm } \\
\text { al } \\
\text { unifor } \\
\text { mity } \\
\text { coeffic } \\
\text { ient, } \mathrm{r}\end{array}$ \\
\hline 1. & MH-101 & $6,1 * 4=24,4$ & 3,47 & 0,81 \\
\hline 2. & MH-101 & $6,1 * 4=24,4$ & 3,24 & 0,76 \\
\hline 3. & MH-101 & $6,1 * 2=12,2$ & 3,10 & 0,72 \\
\hline 4. & MH-2-3 & $5,7 * 2=11,4$ & $3,44 / 0,87=3,95$ & 0,80 \\
\hline 5. & MH-2-3 & $5,7 * 2=11,4$ & $3,27 / 0,87=3,76$ & 0,76 \\
\hline 6. & MH-1-2 & $9,1 * 3=27,3$ & 3,50 & 0,82 \\
\hline 7. & MH-1-2 & 9,1 & 3,34 & 0,78 \\
\hline 8. & MH-200 & 8,4 & $3,39 / 0,87=3,9$ & 0,79 \\
\hline 9. & MH-200 & 8,4 & $3,27 / 0,87=3,76$ & 0,76 \\
\hline 10. & MH-250 & $8,4 * 2=16,8$ & $3,39 / 0,87=3,9$ & 0,79 \\
\hline 11. & MH-5,-6 & $4,5 * 2=9$ & 3,16 & 0,73 \\
\hline 12. & MH-3,-4 & $4,2 * 4=16,8$ & 3,14 & 0,72 \\
\hline 13. & MH-7,-8 & $9,1 * 4=36,4$ & 3,63 & 0,84 \\
\hline 14. & MH-11 & $7,9 * 2=15,8$ & 3,67 & 0,85 \\
\hline 15. & MH-28 & $4,2 * 4=16,8$ & 3,76 & 0,86 \\
\hline 16. & MH-15 & $8,7 * 2=17,4$ & 3,46 & 0,80 \\
\hline 17. & MH-61 & $8 * 2=16$ & 3,37 & 0,78 \\
\hline 18. & MH-62 & $4,3 * 4=8,6$ & 3,14 & 0,72 \\
\hline & Total: & 299,2 & 3,48 & 0,79 \\
\hline
\end{tabular}

In that way, for determination of the specific heat losses of a three-layered wall panel of MH-7 type, the calculation of the temperature panels were conducted of three two-dimensional models in the field of flexible metallic bonds. The considered approach of the determination of resistance referred to heat transfer allows to define the construction of an edifice, to reveal the weakest in the heat technology respect elements of the fencing in constructions, and to take measures for their warming. So, instead of metallic flexible bonds are used from composite materials, basalt-plastic materials;developed new technical solutions of the seams of the outer walling slabs of floors, units abutting window units with exterior walls, seams balconies, etc.The method of calculation of specific heat losses through the dedicated line and point of the model elements of the external envelope is sufficiently transparent, allows you to define a thermal resistance of enclosing structures of buildings with complex geometry and high thermal heterogeneity.

\section{Acknowledgment}

The Research was conducted by JSC "INSOLARINVEST" with the financial support of the Ministry of Education and Science of Russia. Unique identifier of the project RFMEFI57614X0034.

\section{References}

1. EN ISO 6946: 2007 Building components and building elements - Thermal resistance and thermal transmittance - Calculation method.

2. ISO 14683: 2007 Thermal bridges in building construction - Linear thermal transmittance Simplified methods and default values.

3. ISO 10211: 2007 Thermal bridges in building construction - Heat flows and surface temperatures - Detailed calculations.

4. SP 50.13330.2012 Thermal protection of buildings.

5. G. P. Vasilyev, N. V. Peskov V. A. Lichman, V. F. Gornov, M. V. Kolesova. "Modeling the thermal regime of underground structures based on seasonal temperature changes". Scientifictechnical and production journal «Housing construction» V. 82012 p.1-5.

\section{Conclusions}

